\title{
Análise descritiva da diarreia em uma coorte de bezerras criadas em sistema de casinhas até cem dias de idade, Município de Piraí, Estado do Rio de Janeiro, Brasil
}

\section{Descriptive analysis of diarrhea in a cohort of calves in individual crates under paddock up to one hundred days of age, Municipality of Pirai, State of Rio de Janeiro, Brazil}

\author{
Thais Ferreira Fagundes ${ }^{1 *}$; Letícia Gabriela Poblete Vidal²; \\ Pedro Afonso Moreira Alves ${ }^{3}$; Wagner de Souza Tassinari ${ }^{4}$; \\ Shana de Matos de Oliveira Coelho ${ }^{4}$; Rita de Cássia Alves Alcântara de Menezes ${ }^{4}$; \\ Adevair Henrique da Fonseca ${ }^{4}$; Maria Julia Salim Pereira ${ }^{4}$
}

\begin{abstract}
Resumo
Este trabalho teve como objetivos descrever a diarreia e a infecção por parasitas e, avaliar a ocorrência de falha na transferência de imunidade passiva e de Escherichia coli enteropatogênica/enteroinvasiva em bezerras do nascimento aos cem dias de idade, criadas em sistema de abrigo individual em piquete. As fezes coletadas, semanalmente, durante o período de setembro de 2009 a junho de 2011 foram examinadas por meio das técnicas de centrífugo-flutuação em solução saturada de açúcar e centrífugosedimentação em formol-éter. O teste de coagulação pelo glutaraldeído a $10 \%$ foi utilizado para verificar a transferência de imunidade passiva. A identificação bacteriológica foi realizada a partir de isolamentos em meios específicos. Cento e dezoito bezerras foram acompanhadas, totalizando 1457 amostras fecais. As taxas de incidência de diarreia e de infecção por Cryptosporidium, G. intestinalis, Eimeria e helmintos foram respectivamente 25,$7 ; 13,2 ; 16,6 ; 26,9$ e 16,7 casos novos por 100 bezerrassemana. A média de idade de bezerras que apresentaram diarreia foi $54,2 \pm 26,6$, quando eliminaram

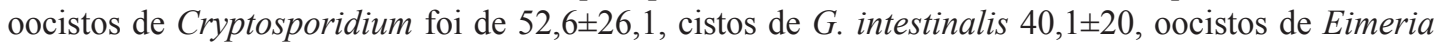
$49,5 \pm 21,8$ e ovos do tipo Strongylida $64,9 \pm 22,3$ dias. Em nenhuma amostra a intensidade de infecção por Cryptosporidium e Giardia foi classificada como alta. Amostras de fezes de 62 bezerras foram submetidas à análise bacteriológica e nenhuma cepa foi caracterizada como E. coli enteropatogência/ enteroinvasiva. Em $69,6 \%$ das bezerras, a quantidade de imunoglobulinas no sangue foi satisfatória. Apesar da alta incidência de diarreia, a letalidade foi baixa, possivelmente devido pouca virulência dos bioagentes e às baixas intensidades das infecções, assim como, aos sistema de administração de colostro e de criação adotado na propriedade. A semelhança entre a idade média das bezerras com diarreia e aquelas que eliminaram oocistos de Cryptosporidium spp. indica que provavelmente este bioagente, dentre os pesquisados, é o principal responsável pelos quadros diarreicos observados.

Palavras-chave: Estudo longitudinal, sistema de criação de bezerrros, colostro
\end{abstract}

\footnotetext{
${ }^{1}$ Discente de Doutorado, Universidade Federal Rural do Rio de Janeiro, UFRRJ, Seropédica, RJ. E-mail: tha.fagundes@gmail. com

${ }^{2}$ Discente de Mestrado, UFRRJ, Seropédica, RJ. E-mail: let_vet@yahoo.com.br

${ }^{3}$ Pesquisador, Estação Experimental de Seropédica, PESAGRO-RIO, Seropédica, RJ. E-mail: gir.leiteiro@ig.com.br

${ }^{4}$ Profs., UFRRJ, Seropédica, RJ. E-mail: wtassinari@gmail.com; shana@ufrrj.br; cassia@ufrrj.br; fonseca@ufrrj.br; m.salim@ ufrij.br

* Autor para correspondência
} 


\begin{abstract}
This study aimed to describe the diarrhea and parasites infection, evaluate the occurrence of failure of passive immunity transference and Escherichia coli EIEC/EPEC in heifer calves in calves from birth to one hundred days old, reared in individual crates under paddock. The feces collected weekly during the period September 2009 to June 2011 were examined by flotation in saturated sugar and centrifugal sedimentation in formalin-ether. The coagulation test by $10 \%$ glutaraldehyde was used to verify the transfer of passive immunity. The bacterial identification was performed from isolates in specific media. One hundred and eighteen heifers were followed, totaling 1457 fecal samples. The incidence rates of diarrhea and infection by Cryptosporidium, G. intestinalis, Eimeria and helminths were respectively 25.7, 13.2, 16.6, 26.9 and 16.7 new cases per 100 calves week. The average age of calves that had diarrhea was $54.2 \pm 26.6$, when they eliminated Cryptosporidium oocysts was $52.6 \pm 26.1$, cysts of G. intestinalis $40.1 \pm 20$ oocysts of Eimeria $49.5 \pm 21.8$ and Strongylida type eggs $64.9 \pm 22.3$ days. In none sample the intensity of infection by Cryptosporidium and Giardia was high. Samples of 62 calves were submited to bacteriological analysis and no sample was characterized as E. coli EPEC/EIEC. In $69.6 \%$ of the calves, the amount of immunoglobulins was satisfactory. Despite the high incidence of diarrhea, mortality was low, due to low virulence of bioagents and low intensities of infection, as well as the system administration of colostrum and adopted creating the property. The similarity between the average age of calves with diarrhea and those eliminated Cryptosporidium spp. probably indicates that this bioagent, among those surveyed, is primarily responsible for diarrheal observed frames.
\end{abstract}

Key words: Longitudinal study, calves rearing system, colostrum

\section{Introdução}

A diarreia é considerada uma das mais importantes causas de mortalidade em bezerros, e tem uma complexa etiologia podendo ser causada por vários micro-organismos como, Escherichia coli, Campylobacter spp., rotavirus, e protozoários dos gêneros Cryptosporidium, Giardia e Eimeria (SNODGRASS et al., 1986; de La FUENTE et al., 1999; GARCÍA et al., 2000; LASSEN et al., 2009; BARTELS et al., 2010).

Dentre as bactérias identificadas em fezes de bezerros, a mais comumente relacionada à ocorrência de diarreia e perdas econômicas é $E$. coli enterotoxigênica, principalmente em animais com até 30 dias de idade, sendo identificada em maior porcentagem em bezerros de 15 a 21 dias por De La Fuente et al. (1998).

Bezerros jovens desempenham um importante papel na manutenção da infecção por Cryptosporidium no rebanho e representam um grande risco zoonótico (BROOK et al., 2008, 2009). Mas, o risco de infecção diminui significativamente com o aumento da idade do animal (MALDONADO-CAMARGO et al., 1998;
MOHAMMED; WADE; SCHAAF，1999). Além disso, animais jovens são mais sensíveis à infecção clínica por espécies do gênero Eimeria, que estão envolvidas em perdas econômicas, por causarem diarreia (CORNELISSEN et al., 1995; MATJILA; PENZHORN, 2002). A ocorrência das espécies de Eimeria varia de acordo com a idade dos animais hospedeiros (MENEZES; LOPES, 1995).

Giardia intestinalis (syn. G. lamblia, $G$. duodenalis) é um protozoário que pode ou não estar relacionado a quadros diarreicos em vários hospedeiros e é encontrado em bezerros de rebanhos leiteiros de diversos países (GUIMARÃES; GUEDES; CARVALHO, 2001; MARK-CAREW et al., 2012; GEURDEN et al., 2012; MUHID et al., 2012). Assim como as protozooses, as helmintoses são um problema na pecuária, pois quando não controladas, podem levar a perda de peso e morte dos bezerros (LIMA et al., 1997).

As taxas de morbidade e de mortalidade nas infecções respiratórias e intestinais em animais jovens são maiores nos que não absorveram quantidade adequada de imunoglobulinas, seja por ingestão insuficiente de colostro, por falha na 
absorção intestinal de imunoglobulinas ou baixa concentração de imunoglobulinas no colostro (BOYD, 1972; TENNANT et al., 1979; FURMANFRATCZAK; RZASA; STEFANIAK, 2011).

$\mathrm{Na}$ literatura há vários estudos transversais sobre a ocorrência de diarreia e infecção por Giardia, Cryptosporidium, Eimeria e helmintos em bovinos (PÉREZ et al., 1998; BARWICK et al., 2003; JIMÉNEZ et al., 2010; BARTELS et al., 2010; GEURDEN et al., 2012; MUHID etal., 2012) que por suas características permitem avaliar a magnitude do problema por meio da análise da prevalência pontual, que é uma medida estática, não permitindo avaliar a força da morbidade. Poucos estudos são do tipo longitudinal (SIVULA et al., 1996; CASTROHERMIDA et al., 2002; SVENSSON et al., 2003, SANTÍN; TROUT; FAYER, 2008, 2009), cuja abordagem é adequada para observação da dinâmica da infecção por se basear em mais de uma amostra do mesmo indivíduo (MEDRONHO et al., 2008; MARTIN; MEEK; WILLEBERG, 1997).

No Brasil, o sistema de criação em abrigo individual em piquete, conhecido como casinhas, foi desenvolvido para minimizar os problemas sanitários das criações em bezerreiros e vem sendo utilizado no manejo intensivo. Segundo Oliveira, Azevedo e Melo (2005) o sistema tem diversas vantagens como, por exemplo, proteção contra excesso de chuva e sol, facilidade de limpeza e deslocamento evitando acúmulo de umidade. Além disso, o uso de casinhas pode evitar a reinfecção das bezerras por micro-organismos que possam permanecer viáveis no local, já que podem ser deslocadas e tem facilidade de limpeza, reduzindo assim o risco de diarreia. Ademais, Machado Neto et al. (2004) ao compararem a casinha com bezerreiro coletivo, pasto com abrigo, pasto e outros tipos encontraram menores taxas de mortalidade em bezerros mantidos em casinhas.

Com objetivo de melhorar rendimento das bezerras criadas na fazenda, onde foi realizado o estudo, este tipo de abrigo era utilizado, assim como tecnologias em relação à reprodução e melhoramento animal. Porém, de acordo com informações do administrador, apesar dos cuidados e investimentos, ocorriam muitas perdas relacionadas à ocorrência de diarreia. Embora, haja difusão desse sistema de criação, até o momento não existem estudos, disponíveis na literatura, sobre os aspectos epidemiológicos da diarreia em bezerras criadas neste tipo de instalações.

Assim, este trabalho teve como objetivos: 1) estimar a incidência de diarreia e de infecção por parasitas; 2) verificar a distribuição da idade média e a idade de primeira observação de diarreia e infecção por parasitas e sua intensidade; 3) avaliar a ocorrência de falha na transferência de imunidade passiva e 4) diagnosticar a ocorrência de Escherichia coli enteropatogência e enteroinvasiva por meio de estudo prospectivo em bezerras do nascimento aos cem dias de idade criadas em sistema de casinhas individuais no Município de Piraí, Estado do Rio de Janeiro.

\section{Material e Métodos}

Localização da fazenda, manejo dos animais $e$ desenho do estudo

Uma coorte de bezerras nascidas no período de setembro de 2009 a junho de 2011 foi acompanhada do nascimento aos cem dias de idade. As bezerras eram mestiças, com graus variados de sangue da raça holandesa preta e branca, criadas em um estabelecimento para produção de leite, no Município de Piraí (latitude 22 37'45" sul e longitude $43^{\circ} 53^{\prime} 53^{\prime \prime}$ oeste, estando a uma altitude de 387 metros). O estabelecimento mantinha instalações do tipo "freestall" para as vacas lactantes e abrigos individuais em piquete (casinhas) para as fêmeas até 100 dias. Os machos eram vendidos logo após o nascimento. As bezerras eram separadas das mães imediatamente após o nascimento e colocadas em casinhas. A casinha é um tipo de abrigo individual onde o animal fica protegido por uma cobertura com telha permanecendo com movimentação limitada 
ao seu interior e arredores por ser mantido em uma coleira presa por uma corrente fixada ao chão. Desta forma, a bezerra não tem contato direto com o animal da casinha ao lado. Nesses abrigos, recebiam em mamadeira seis litros de colostro, divididos em duas frações. O colostro selecionado unicamente de vacas, após um teste usando colostrômetro, era armazenado em freezer e descongelado na hora da administração às bezerras. Cada casinha tinha dois baldes: um para o fornecimento de ração, oferecida desde o nascimento, e outro para leite e água, proveniente de poço artesiano. $\mathrm{O}$ fornecimento de leite era realizado até 90 dias após o nascimento, sendo de 0 a 30 dias -3 litros de manhã e 3 litros à tarde, dos 31 a 60 dias - 2 litros de manhã e 2 litros à tarde, de 61 a 90 dias - 2 litros pela manhã. De 90 a 100 dias não era fornecido leite, apenas água e ração. A higienização dos baldes era realizada pela manhã utilizando-se apenas água. O manejo adotado pela fazenda, também incluía a administração do antiparasitário doramectina ${ }^{5}$ uma vez ao mês, com o propósito de prevenir e tratar parasitoses por nematóides e artrópodes. Além disso, em casos graves de diarreia era administrada sulfametazina sódica ${ }^{6}$ e, em casos de tristeza parasitária, oxitetraciclina ${ }^{7}$ com diaceturato de diazominodibenzamidina ${ }^{8}$. O tratamento do umbigo era realizado com solução de álcool iodado.

Semanalmente, foram realizadas visitas para coleta de fezes, registro dos episódios de diarreia e de outras alterações clínicas.

\section{Definição de caso de diarreia}

Os casos de diarreia foram classificados de acordo com as características das fezes e pela sua presença no períneo e/ou cauda do animal sempre pelo

5 Dectomax ${ }^{\circledR}$ - solução injetável a 1\%, Pfizer Saúde Animal, Guarulhos, SP, Brasil.

${ }^{6}$ Biosulfan ${ }^{\circledR}$ - solução injetável, Biofarm Química e Farmacêutica, Jaboticabal, SP, Brasil.

7 Terramicina® /LA solução injetável, Pfizer Saúde Animal, Guarulhos, SP, Brasil

8 Diaseg ${ }^{\circledR}$ solução injetável a 7\%, Schering-Plough Veterinária, Cotia, SP, Brasil. mesmo observador. No entanto, pela periodicidade do estudo, com coletas semanais, apenas foram considerados casos de diarreia as amostras fecais classificadas como diarreicas no dia da coleta, não sendo possível saber se o animal teve diarreia nos outros dias da semana e quanto tempo persistiu o quadro. As amostras fecais foram classificadas adotando-se o seguinte critério: "normal" ou não diarreicas, quando consistência firme, cor marrom, períneo e cauda da bezerra apresentaram-se limpos e secos; diarreicas, quando consistência pastosa ou aquosa, períneo e/ou cauda do animal sujos com fezes.

\section{Análise parasitológica}

Durante as visitas semanais foram coletadas amostras de fezes, diretamente da ampola retal, acondicionadas em sacos plásticos identificados e mantidas sob refrigeração até o momento do processamento que ocorreu em média duas horas após a coleta.

A infecção por Cryptosporidium spp. e Giardia spp. foi diagnosticada pela presença de oocistos/ cistos nas fezes, utilizando-se a técnica de centrífugo-sedimentação em formol-éter (BASSO; VENTURINI; RISSO, 1998), e observação em microscópio óptico em objetiva de $1000 \mathrm{X}$ com óleo de imersão. Para a pesquisa de Eimeria e ovos de nematóides foi utilizada a técnica de centrífugoflutuação em solução saturada de açúcar (densidade 1.20 - 1.25), como descrita por Menezes e Lopes (1995) para contagem de oocistos por grama de fezes (OoPG) e ovos por grama de fezes (OPG). Após a contagem dos ovos de nematóides, as amostras positivas foram separadas para a realização de coproculturas, seguindo-se a técnica descrita por Roberts e O'Sullivan (1950) para a obtenção de larvas infectantes $\left(\mathrm{L}_{3}\right)$ e posterior identificação dos gêneros de nematóides presentes nas fezes das bezerras, segundo Ueno e Gonçalves (1998). Todas as amostras positivas para ovos de nematóides na coleta da semana eram concentradas 
para a realização de apenas uma coprocultura, e identificação das espécies que ocorriam no rebanho.

A liberação de oocistos de Cryptosporidium spp. e cistos de Giardia spp. foi classificada semiquantitativamente segundo o número de oocistos/ cistos por campo, em 20 campos selecionados aleatoriamente em aumento de 1000X: ausência de cistos, intensidade baixa ( $=1$ cisto), intensidade moderada (2-5 cistos), intensidade alta (6-10 cistos) e intensidade muito alta ( $>10$ cistos) (CASTROHERMIDA et al. 2002).

As amostras positivas para oocistos de Eimeria spp. foram classificadas de acordo com a intensidade de infecção em moderada (5-700) e alta (>700). Este critério foi adotado por extrapolação feita com base em Ueno e Gonçalves (1998) que consideram como moderada (200-700) e pesada (>700), a eliminação de OPG, no caso de infecção mista em bovinos. Assim, considerando que as infecções por espécies de Eimeria são multiespecífcas e apresentam variações semelhantes às citadas por Ueno e Gonçalves (1998), adotaram-se os critérios relatados por esses autores para graduar, neste estudo, a intensidade de infecção por Eimeria e liberação de ovos de nematóides.

Uma parte das fezes de cada bezerra positiva para infecção por Eimeria, de acordo com a intensidade de infecção (moderada e alta), foi submetida ao processo de esporulação e conforme descrito por Matjila e Penzhorn (2002) e mantida a temperatura ambiente por sete dias. Após a esporulação dos oocistos foi realizada a identificação percentual das espécies de Eimeria, segundo os critérios apresentados por Levine (1985) e Eckert et al. (1995).

\section{Análise bacteriológica}

Amostras de fezes diarreicas de sessenta e duas bezerras foram enviadas ao Laboratório de Bacteriologia do Instituto de Veterinária da Universidade Federal Rural do Rio de Janeiro.
Essas amostras de fezes foram repicadas nos meios ágar MacConkey ${ }^{9}$ e ágar eosina azul de metileno ${ }^{1}$. Para a pesquisa de bactérias pertencentes aos gêneros Salmonella e Shigella, as amostras foram enriquecidas em caldo tetrationato de sódio e posteriormente repicadas em ágar SalmonellaShigella ${ }^{1}$. Após o período de incubação de 18 a 24 horas a $37^{\circ} \mathrm{C}$, as colônias foram observadas quanto à forma, cor, bordas, dentre outras características fenotípicas.

Após diferenciação prévia das colônias, estas foram submetidas à coloração de Gram para observação das características morfológicas e tintoriais e, teste de hidrólise ao Hidróxido de potássio a 3\% para confirmação do Gram. Posteriormente, foram realizadas as seguintes provas de identificação das espécies: comportamento em ágar tríplice açúcar-ferro, comportamento em meio SIM ( $\mathrm{H}_{2} \mathrm{~S}$ Indol Motilidade), produção de ácidos a partir da glicose, fermentação de açúcares, teste Voges Proskauer, teste vermelho de metila, redução do nitrato, produção de gelatinase, degradação de citrato e malonato, e outros diferenciais de acordo com o microorganismo envolvido (KONEMAN et al., 2008).

Os isolados caracterizados como E. coli foram enviados ao Laboratório de Enterobactérias, Centro de Referência Nacional de Enteroinfecções Bacterianas, situado na Fundação Oswaldo Cruz Rio de Janeiro para pesquisa de cepas EPEC (E.coli enteropatogênica) e EIEC (E.coli enteroinvasiva), segundo metodologia de soroaglutinação estabelecida pelo próprio laboratório.

\section{Coleta de sangue e teste do glutaraldeído}

Amostras sanguíneas de todas as bezerras recrutadas foram coletadas por meio de punção da veia jugular, usando agulhas descartáveis e tubos contendo vácuo. A coleta de sangue foi realizada em todas as bezerras, após pelo menos seis horas

\footnotetext{
9 Himedia ${ }^{\circledR}$-Mumbai, India.
} 
da ingestão do colostro, no primeiro contato com o animal. $\mathrm{O}$ soro obtido foi congelado $\left(-20^{\circ} \mathrm{C}\right)$ até a realização do teste do glutaraldeído, de acordo com Charles, Campos e Liziere (1994). Foram consideradas como padrão, três amostras de soro de bezerros que sabidamente ingeriram colostro. As reações positivas foram caracterizadas pela formação de uma massa firme e opaca no fundo do tubo, que não se movia quando o tubo era inclinado (em média, 1,46g de imunoglobulina/dl). A reação incompleta foi caracterizada por formação de massa semi-sólida (em média, 0,6g de imunoglobulina/dl), e a reação negativa não havia mudanças detectáveis no soro (em média, 0,18g de imunoglobulina/dl) (CHARLES; CAMPOS; LIZIERE, 1994). Os resultados considerados no teste de glutaraldeído foram os obtidos 60 minutos após a adição do reagente ao soro, uma vez que a reação de solidificação depende da concentração de imunoglobulinas e pode ocorrer tardiamente (TENNANT et al., 1979).

\section{Análise estatística}

O cálculo da taxa de incidência foi realizado considerando-se no numerador o número de casos novos dos eventos estudados (diarreia e infecção por parasitos) e no denominador o somatório do período de tempo durante o qual cada bezerra esteve exposta ao risco de diarreia e de infecção (MARTIN; MEEK; WILLEBERG, 1997).

Foram calculadas as proporções dos animais que apresentaram diarreia e infecção por parasitos, tendo como numerador o número de bezerras que apresentaram os eventos estudados durante o período do estudo e no denominador o número de bezerras expostas ao risco. O calculo da letalidade foi realizado considerando-se no numerador $o$ número de mortos por diarreia e no denominador o número de animais que apresentaram diarreia.

Modelos logísticos aditivos generalizados (do inglês, GAM) (HIN et al., 1999, WOOD, 2006) foram utilizados para descrever a relação funcional entre idade e o risco do animal ser acometido por diarreia e pelos bioagentes encontrados. As análises estatísticas foram realizadas com auxílio do pacote estatístico R (R DEVELOPMENT CORE TEAM, 2011).

\section{Resultados}

Neste estudo foram acompanhadas 118 bezerras do nascimento até o término da pesquisa, morte ou soltura, totalizando 1.457 amostras fecais analisadas, em 94 semanas. Dessas amostras, 29,0\% (423) foram classificadas como diarreicas e 71,0\% (1034) como normais. Quadros diarreicos foram observados em 95,7\% (113/118) das bezerras e $3,4 \%$ (4/118) morreram, porém destas, apenas uma apresentava quadro diarreico, e a letalidade foi de $0,88 \%$. As taxas de incidência observadas foram: 25,7 casos novos por 100 bezerras-semana (113 casos novos/439 bezerras-semana) para diarreia; 13,2 casos novos por 100 bezerras-semana (98 casos novos/739 bezerras-semana) para infecção por Cryptosporidium; 16,6 casos novos por 100 bezerras-semana (94 novos casos/566 bezerrassemanas) para infecção por $G$. intestinalis e 26,9 casos novos por 100 bezerras-semana (113 casos novos/ 420 bezerras-semana) para infecção por Eimeria. A taxa de incidência de eliminação de ovos de helmintos foi de 16,7 casos novos por 100 bezerras-semana (95 casos novos/ 568 bezerrassemana).

Foram identificados ovos da ordem Strongylida, e esporadicamente, ovos de Strongyloides, Trichuris e Moniezia, respectivamente em 10, 12 e 6 animais. Após coprocultura, as larvas identificadas, com base em Ueno e Gonçalves (1998), foram dos gêneros: Trichostrongylus, Haemonchus e Chabertia, sendo o gênero Haemonchus o mais encontrado. Dentre os protozoários, foram identificados oocistos de Cryptosporidium e cistos de Giardia e nove espécies de Eimeria, que após esporulação foram identificadas como E. subspherica, E. zuernii, E. ellipsoidalis, E. cylindrica, E. alabamensis, E. bovis, 
E. canadensis, E. wyomingensis, E. auburnensis. Os oocistos da espécie $E$. bovis foram mais observados em infecções de intensidade moderada e $E$. ellipsoidalis naquelas de intensidade alta.

Oocistos de Cryptosporidium foram eliminados por 83,0\% (98/118) dos animais, cistos de $G$. intestinalis por 80,0\% (94/118), oocistos de Eimeria por $95,7 \%$ (113/118) e ovos de helmintos por $64,4 \%$
(76/118). Nenhuma amostra teve a intensidade de infecção por Cryptosporidium e Giardia classificada como alta ou muito alta. O resultado da pesquisa de oocistos de Eimeria e de Cryptosporidium, cistos de Giardia e ovos do tipo Strongylida, classificado de acordo com intensidade de infecção e presença ou ausência de diarreia está demonstrado na Tabela 1.

Tabela 1. Resultado da pesquisa de oocistos de Eimeria e de Cryptosporidium, cistos de Giardia, e ovos do tipo Strongylida, classificado segundo a intensidade de infecção e presença ou ausência de diarreia.

\begin{tabular}{lll}
\hline \multirow{2}{*}{ Intensidade } & \multicolumn{2}{c}{ Amostras de fezes (\%) } \\
\cline { 2 - 3 } $\begin{array}{c}\text { Cryptosporidium } \\
\text { negativa }\end{array}$ & Niarreicas (n=423) & \\
baixa & $349(82,5 \%)$ & $905(87,5 \%)$ \\
moderada & $68(16,1 \%)$ & $120(11,6 \%)$ \\
Giardia & $6(1,4 \%)$ & $9(0,8 \%)$ \\
negativa & & \\
baixa & $361(85,3 \%)$ & $860(83,3 \%)$ \\
moderada & $34(8,1 \%)$ & $111(10,6 \%)$ \\
Eimeria & $28(6,6 \%)$ & $63(6,1 \%)$ \\
negativa & & $589(56,9 \%)$ \\
moderada & $255(60,2 \%)$ & $383(37,0 \%)$ \\
alta & $143(33,4 \%)$ & $62(5,9 \%)$ \\
Strongylida & $25(5,9 \%)$ & \\
negativa & & $923(89,2 \%)$ \\
moderada & $382(90,3 \%)$ & $110(10,6 \%)$ \\
alta & $41(9,6 \%)$ & $1(0,09 \%)$ \\
\hline
\end{tabular}

Fonte: Elaboração dos autores.

O primeiro episódio de diarreia foi observado em uma bezerra com apenas cinco dias de idade, oocistos de Cryptosporidium foram observados em fezes de bezerras também a partir de cinco dias de vida e a média de idade da primeira eliminação foi igual a 41,2 $\pm 25,7$ dias. Cistos de Giardia foram observados em fezes de bezerras a partir de oito dias de idade, independentemente da ocorrência de diarreia, tendo como média de primeira eliminação 27,2 $\pm 14,3$ dias; oocistos de Eimeria foram eliminados a partir de 10 dias de vida com média de 26,7 $\pm 13,7$ dias e ovos do tipo Strongylida a partir de 15 dias e a média da idade de primeira eliminação foi de 54,2 223,0 dias.
A média de idade de bezerras que apresentaram diarreia foi $54,2 \pm 26,6$, com idade modal de 79 dias. Já a idade das bezerras quando eliminaram oocistos de Cryptosporidium foi 52,6 $\pm 26,1$ (moda= 65 dias); quanto à eliminação de cistos de $G$. intestinalis foi $40,1 \pm 20$ dias (idade modal de 19 dias); oocistos de Eimeria aos 49,5 $\pm 21,8$ dias (moda= 25 dias); e ovos do tipo Strongylida aos $64,9 \pm 22,3$ dias $(\operatorname{moda}=68$ dias).

A análise pelo GAM sugere uma relação linear entre a idade e a infecção por Cryptosporidium, e uma relação não-linear para as infecções por 
G. intestinalis, Eimeria, e helmintos. O risco de infecção por Cryptosporidium aumenta conforme aumenta a idade das bezerras. Já a infecção por G. intestinalis aumenta até em torno dos 25 dias e depois decresce. Sentido semelhante ao observado no gráfico que demonstra a relação entre a infecção por Eimeria, que tem o pico de eliminação de oocistos aos 32 dias, aproximadamente. $\mathrm{O}$ risco de liberação de ovos de helmintos é maior em bezerras acima de 45 dias. Já o risco de ocorrência de diarreia oscila de acordo com a idade dos animais, sendo maior nas primeiras semanas e em torno do $80^{\circ}$ dia de vida (Figura 1).

A idade média das bezerras quando da coleta de sangue para avaliação da transferência de imunidade passiva foi de $4 \pm 2,7$ dias. Esta variação se deu devido ao manejo da propriedade, e a periodicidade semanal do estudo.

A reação ao teste do glutaraldeído foi positiva para $82(69,5 \%)$ bezerras, incompleta em $18(15,2 \%)$ bezerras, e negativa para $18(15,2 \%)$, ou seja, não houve aglutinação do soro sanguíneo. Os animais com falha na transferência de imunidade (negativos e incompletos para o teste do glutaraldeido) possuíam idade entre 0 a 7 dias e os que não apresentaram falha tinham idade entre 0 a 13 dias de nascidos, portanto a falha na transferência de imunidade passiva não esteve ligada a idade dos animais quanto ao tempo decorrido entre o fornecimento do colostro e a coleta do soro.

Nas amostras de sessenta e duas bezerras foram diagnosticadas as seguintes espécies de bactérias: E. coli $(54-87,1 \%)$, Proteus mirabilis $(5-8,1 \%)$, P. vulgaris(4 - 6,4\%), Citrobacter diversus (20$32,3 \%)$, C. freundii $(1-1,6 \%)$, Shigella spp. (1 $1,6 \%)$, S. sonneo (2- 3,2\%), Edvardstella tarda (3 -4,83\%), Salmonella spp. (2-3,2\%), Enterobacter spp. $(1-1,6 \%)$, E. sakazakii $(1-1,6 \%), \quad$ E. cloacae $(1-1,61 \%)$, Klebsiella oxytoca $(1-1,6 \%)$, Providencia stuartii (1 - 1,6\%), sendo 26 amostras com infecção mista. Nenhum isolado caracterizado como E. coli aglutinou nos antissoros EPEC/EIEC.

Figura 1. Modelos logísticos aditivos generalizados para o estudo da relação funcional do risco do animal: (A) eliminar oocistos de Cryptosporidium spp.; (B) eliminar cistos de Giardia intestinalis; (C) eliminar oocistos de Eimeria spp.; (D) eliminar ovos do tipo Strongylida; (E) apresentar diarreia de acordo com a idade em bezerras criadas no sistema de casinhas em uma produção leiteira do município de Piraí, no estado do Rio de Janeiro.
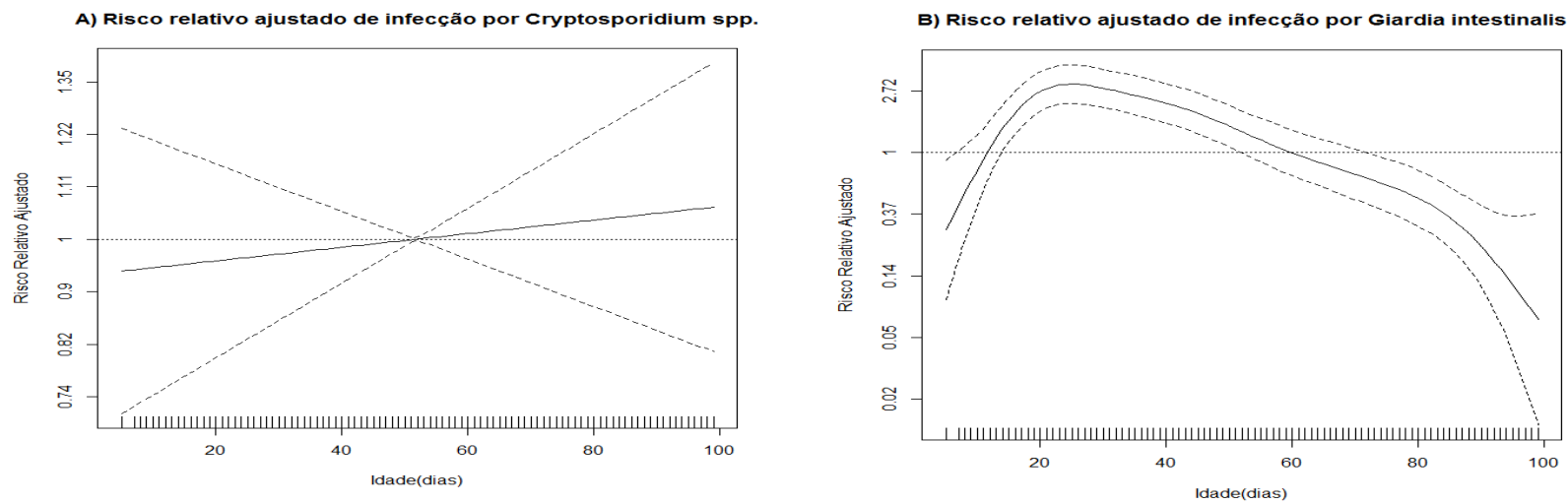

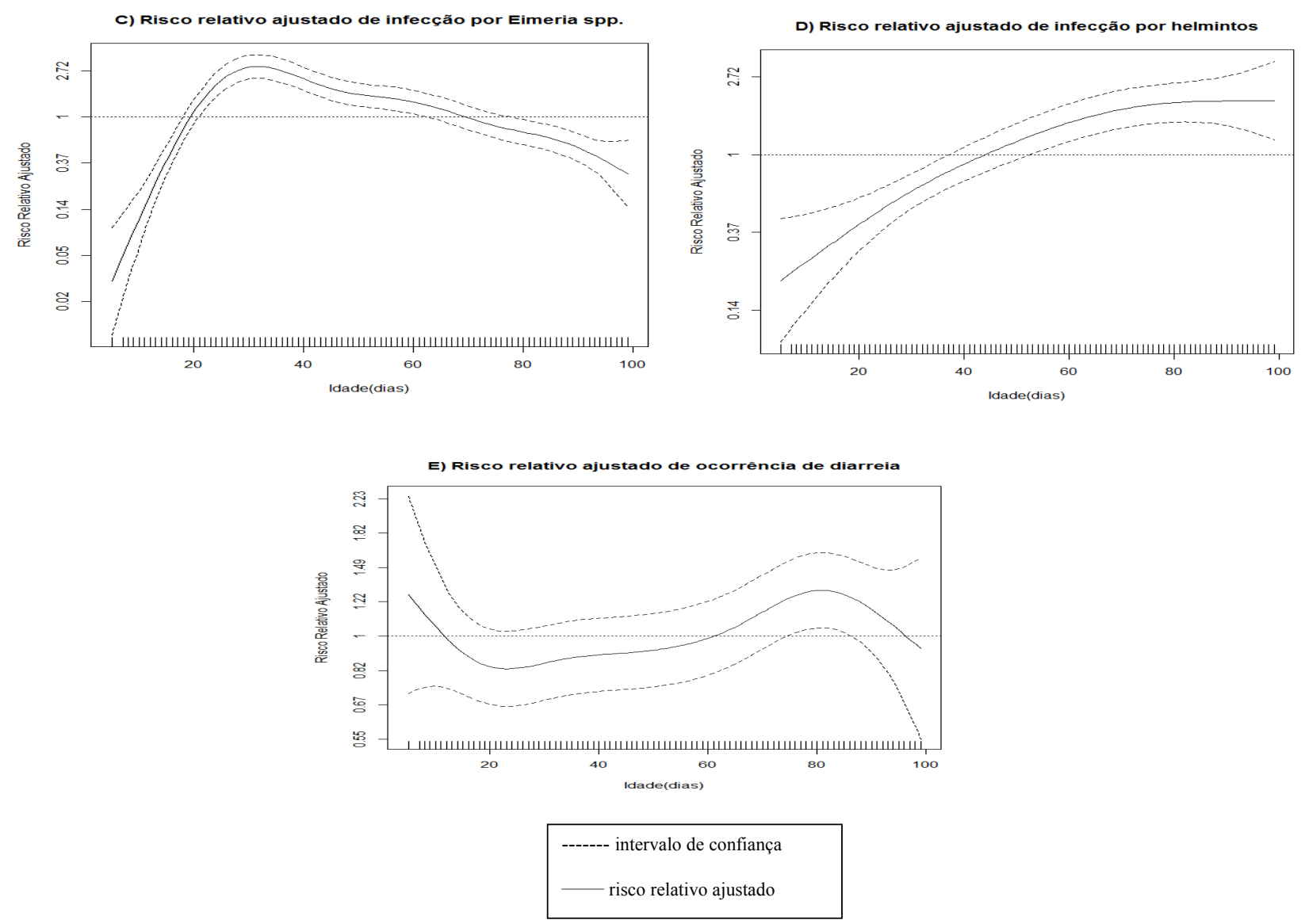

Fonte: Elaborações dos autores.

\section{Discussão}

O percentual de 95,7 (113/118) bezerras com diarreia no presente estudo está bem acima dos $19,75 \%$ (390/1974) observados por Botteon et al. (2008) em bezerros lactentes de 1 a 90 dias em 20 propriedades, criadas em ambos os sistemas de abrigo, casinhas e bezerreiros coletivos, nos municipios de Valença e Rio das Flores, ambos no Estado do Rio de Janeiro e Rio Preto, Estado de Minas Gerais. Não obstante, a maior proporção de bezerras com fezes não normais foi observada em $39 \%(46 / 118)$, na segunda semana de vida, seguida de $21 \%(25 / 118)$ na terceira semana de vida e de $7 \%(8 / 118)$ na primeira, resultado que se aproxima ao obtido por Bartels et al. (2010), na Holanda, mas em estudo transversal, onde a proporção de bezerros com fezes não normais foi maior na segunda
$(51,6 \%)$ que na primeira $(38,2 \%)$ e terceira $(37,8 \%)$ semanas de idade.

Na Costa Rica, Pérez et al. (1998) coletaram amostras de fezes, sendo que 186 eram diarreicas e 194 eram normais, dentre as diarreicas, três amostras $(1,61 \%)$ apresentaram Salmonella spp., e 2\% dos bezerros com diarreia reagiram com antissoros de E.coli enteropatogênica. Já o percentual de amostras positivas para Samonella spp. foi superior no presente estudo $(3,22 \%)$ onde das 62 amostras analisadas, duas eram positivas para o gênero. Neste estudo nenhum isolado caracterizado como E. coli, aglutinou nos antissoros EPEC/EIEC, no entanto, Saridakis et al. (1997) identificaram E.coli enteropatogênica em amostras de fezes de 153 bezerros no estado do Paraná, demonstrando assim sua ocorrência no rebanho brasileiro. 
As taxas de incidência obtidas podem estar subestimadas, tendo em vista a periodicidade semanal das coletas, quando o ideal seria a observação e coleta de amostras diariamente. Mesmo assim, a taxa de incidência de diarreia foi alta, contrastando com taxas bem mais baixas ( 1,05 e 0,88 por 100 bezerras semanas) registradas em bezerros do nascimento até 16 semanas e do nascimento até 90 dias, com observação diária, respectivamente, nos Estados Unidos e na Suécia (SIVULA et al., 1996; SVENSSON et al., 2003). No entanto, a mortalidade por diarreia $0,84 \%$ (1/118) no presente estudo, está abaixo dos 3,31\% (28/843) relatados por Sivula et al. (1996). As diferenças entre os resultados deste e dos estudos citados podem ser atribuídas em parte as diferentes metodologias usadas, a região e manejo dos animais, que inclui o alojamento dos bezerros (individual ou coletivo), origem do colostro (congelado e oriundo de banco ou fresco e da própria mãe) e forma de administração de colostro.

Quanto às taxas de incidência de infecção, a por Cryptosporidium no presente estudo foi alta (13,2 casos por 100 bezerras-semana), quando comparado com pesquisa realizada nos Estados Unidos por Starkey et al. (2005), onde a incidência, foi de 1,4 casos por 100 animais-semana. A de animais infectados por $G$. intestinalis (16,6 casos novos por 100 bezerras-semana) também pode ser considerada alta, já que Mark-Carew et al. (2010) em Nova Iorque, relataram taxas de incidência bem mais baixas $(0,28$ casos novos por 100 animaissemana) em coorte de baixo risco de ocorrência de infecção, constituída por fazendas onde em estudo prévio (WADE; MOHAMMED; SCHAAF, 2000b) não foram detectados cistos de Giardia e nem de Cryptosporidium e $(0,77$ casos novos por 100 animais-semana) em coorte de alto risco, formada por fazendas onde foram detectados ambos os protozoários. A diferença entre os resultados dos autores acima e os do presente estudo pode em parte ser explicadas pelas faixas etárias dos animais acompanhados (nos estudos citados variou de $0 \mathrm{a} \geq$
24 meses), uma vez que a intensidade de infecção é menor nos animais adultos, pela sensibilidade das técnicas de diagnóstico utilizadas e pelo período de seguimento das coortes.

A análise do GAM para o risco de ocorrência de diarreia em diferentes faixas etárias mantém aderência com o comportamento da infecção por Cryptosporidium conforme observado por Santín, Trout e Fayer (2008) também em estudo longitudinal. Neste estudo, a relação linear observada entre o risco de infecção por Cryptosporidium e idade difere dos resultados de Brook et al. (2008) que observaram uma relação não linear. No entanto, deve-se considerar a diferença entre os desenhos dos estudos, sendo o primeiro um estudo longitudinal e o segundo um estudo transversal. Além disso, Santín, Trout e Fayer (2008) observaram que cada espécie e genótipo de Cryptosporidium têm padrão de prevalência por período diferente em relação a idade dos bovinos, com C. parvum atingindo o pico na terceira semana de idade e a partir da quarta e décima semanas surgem $C$. bovis e $C$. ryanae que atingem o pico na décima sexta e décima oitava semanas, respectivamente. Considerando-se que no presente estudo, a elaboração do gráfico foi realizada com o resultado do exame de fezes, portanto sem distinção de espécies e tratando-se de um estudo longitudinal, a relação linear observada é explicada. A idade média das bezerras quando eliminaram oocistos de Cryptosporidium em Piraí foi de $52,6 \pm 26,1$ dias. Estes resultados estão de acordo com os de Santín, Trout e Fayer (2008), que também em estudo longitudinal, observaram que bezerras com até 60 dias de idade tem maior risco de eliminação de oocistos. Em relação à precocidade de infecção, a primeira observação de oocistos nas fezes se deu aos cinco dias de idade, mais tardiamente que no estudo realizado por Castro-Hermida et al. (2002), no qual a eliminação de oocistos de $C$. parvum ocorreu a partir de 3 dias. Resultado semelhante ao deste estudo, foi observado por Guimarães et al. (2009) em Minas Gerais, onde a eliminação mais precoce foi aos 6 dias de vida. 
A idade média (40,1 \pm 20 dias) das bezerras que eliminaram cistos de $G$. intestinalis foi maior que a observada por Guimarães, Guedes e Carvalho (2001) em animais da mesma faixa etária $(30 \pm 19$ dias). Porém, menor do que a média encontrada no estudo realizado no Canadá por O'Handley et al. (1999) com bezerros até 120 dias de idade, onde foi de $89 \pm 7,1$. O risco de infecção aumenta até 25 dias (Figura 1B) e depois decresce como observado também em estudo longitudinal conduzido por Santín, Trout e Fayer (2009), no qual o numero de animais infectados aumenta do nascimento até 4 a 5 semanas de idade. Além disso, em estudo transversal em quatro países da Europa, Geurden et al. (2012) observaram que a infecção ocorre em animais com menos de 2 meses e a proporção de positivos decresce gradualmente com a idade.

Em estudo com acompanhamento diário até 60 dias de idade e a partir daí semanal até 100 dias, Guimarães et al. (2009) observaram que o início mais precoce de eliminação de cistos de G. intestinalis nas fezes foi aos 17 dias e o mais tardio aos 25 dias de vida. Ao passo que neste estudo a idade mais precoce foi aos oito dias e a mais tardia, aos 83 dias de vida, com média igual a $27,2 \pm 14,3$ dias. Tal média foi pouco menor que a observada por O'Handley et al. (1999) na primeira eliminação (31,5 \pm 4,1 dias). Já Mark-Carew et al. (2010) detectaram cistos em um bezerro com dois dias de idade, mas a maioria dos bezerros começou a eliminar cistos entre 11 e 20 dias de idade. A variação na precocidade das bezerras em eliminar oocistos/cistos relatada nos diversos estudos pode estar relacionada principalmente ao manejo, ao estado imune dos animais, a intensidade da infecção que por sua vez está relacionada com a dose infectante, assim como, à sensibilidade da técnica utilizada para o diagnóstico e ao tipo de amostragem realizada, já que no presente estudo as amostras não foram coletadas diariamente, o que seria o ideal para determinar o dia exato de primeira eliminação de cistos.

No presente estudo a intensidade de infecção por Cryptosporidium spp. e G. intestinalis pode ser considerada baixa, uma vez que nenhum animal infectado apresentou mais que 5 cistos por campo da lâmina examinada. Silva Junior et al. (2011) também relataram intensidade baixa /média de $G$. intestinalis ( $\leq 10$ cistos/lâmina), porém o uso de metodologia diferente para detecção de oocistos/ cistos não permite comparação entre os resultados.

A presença de cistos de G. intestinalis e oocistos de Cryptosporidium de maneira equivalente em fezes diarreicas e normais corrobora os resultados de Björkman et al. (2003) com G. intestinalis e Brook et al. (2008) que afirmam que a consistência das fezes não tem correlação com eliminação de oocistos de Cryptosporidium. No entanto, são discordantes dos achados de Wade, Mohammed e Schaaf (2000a) que observaram eliminação de cistos de $G$. intestinalis duas vezes maior por animais com fezes diarreicas em relação aqueles com fezes normais. Já em estudo realizado na Índia por Singh et al. (2006) aproximadamente $83 \%$ das amostras fecais com oocistos de Cryptosporidium eram diarreicas, o mesmo aconteceu na Argentina (DEL COCO; CÓRDOBA; BASUALDO, 2008), onde $68 \%$ das bezerros que liberaram oocistos nas fezes tiveram diarreia. $\mathrm{O}$ fato de animais com fezes normais eliminarem oocistos e cistos tanto quanto aqueles com fezes diarreicas tem grande relevância epidemiológica, dado que estes se constituem em portadores assintomáticos, servindo de fonte de infecção para outros hospedeiros susceptíveis.

A eimeriose em bovinos é observada em todas as faixas etárias, mas é mais comum e importante em animais jovens. Em 86 fazendas polonesas a prevalência nos animais investigados foi de $80,1 \%$ em bezerros de 3 a 9 meses, 18,2\% naqueles de um a três meses e $1,7 \%$ entre os com 9 e 18 meses (KLOCKIEWICZ et al., 2007). Em Piraí o maior risco de eliminação de oocistos de Eimeria foi próximo dos 30 dias de vida, porém a idade média de infecção foi igual a 45 dias.

NaHolanda Cornelissen et al.(1995) encontraram doze espécies de Eimeria em 38 rebanhos e 
verificaram que a prevalência variou de acordo com a faixa etária, sendo que E. bovis, E. auburnensis e E. canadensis apresentaram alta prevalência nos animais jovens, que não apresentaram sinais clínicos. No presente estudo, das nove espécies identificadas E. bovis e E. ellipsoidalis foram as mais frequentes, nos animais de até 100 dias de vida. Eimeria bovis é uma das espécies mais diagnosticadas no Brasil, uma vez que muitos estudos relatam sua ocorrência (FIGUEIREDO; SERRA FREIRE; GRISI, 1984; REBOUÇAS et al., 1994; ALMEIDA et al., 2011; BRUHN et al., 2012). No Município de Valença, que está situado na mesorregião do Sul Fluminense, a mesma que o Município de Piraí, no Estado do Rio de Janeiro, foram diagnosticadas dez espécies de Eimeria em bovinos de aptidão leiteira (FIGUEIREDO; SERRA FREIRE; GRISI, 1984), demonstrando assim que em geral a infecção por Eimeria é multiespecífica (MENEZES; LOPES, 1995).

Em estudo realizado por Lima et al. (1997) em Minas Gerais com bezerros do nascimento aos 27 meses de vida, os animais começaram a se infectar por helmintos gastrintestinais antes dos 2 meses de idade, e apresentaram período crítico dessas infecções até os 18 meses. Neste estudo, a maior ocorrência de eliminação de ovos se deu nos animais com mais de 45 dias de vida, tendo idade média de 64,9 dias. No entanto, a taxa de incidência da eliminação de ovos de helmintos foi baixa (7,3 casos novos por 100 bezerras-semana), provavelmente pelo fato da faixa etária estudada ser até 100 dias.

Ainda no estudo conduzido por Lima et al. (1997), o gênero mais encontrado foi Cooperia, sendo Haemonchus o segundo mais incidente. Assim como em estudo realizado no Rio de Janeiro por Pimentel Neto e Fonseca (2002), com bezerros entre 6 e 9 meses onde os helmintos mais prevalecentes foram Cooperia spp. e H. placei com 88 e 10,6\%, respectivamente. No presente estudo, não foi identificado o gênero Cooperia, sendo Haemonchus o mais frequente, seguido de Chabertia, sendo o gênero Haemonchus um helminto causador de anemia, e o gênero Chabertia relacionado com diarreia em animais severamente afetados (SOULSBY, 1982). O controle destas helmintoses necessita de cuidados para se evitar infecções que comprometam o desenvolvimento dos animais.

Em estudo realizado em Araçatuba, Estado de São Paulo com bezerros das raças holandesa (205 animais) e Nelore (208 animais), Feitosa et al. (2010) observaram entre 10 a $20 \%$ de falha de transferência de imunidade passiva dependendo do componente sanguíneo e o padrão escolhido para interpretação. Resultado semelhante ao observado no presente estudo no qual aproximadamente 15\% das bezerras apresentaram falha na transferência de imunidade passiva, $15 \%$ insuficiente transferência e $69,5 \%$ adequada transferência. Aqueles autores demonstraram que as principais perdas de bezerros ocorreram no período próximo do parto pela ocorrência de doenças infecciosas, confirmando a importância da realização de um teste para identificar os bezerros mais susceptíveis nos primeiros dias de vida para realização de manejo diferenciado e maior possibilidade de sucesso na criação. Reforçando a importância da falha na transferência de imunidade passiva, Furman-Fratczak, Rzasa e Stefaniak (2011) relatam que animais com concentrações altas de imunoglobulinas no sangue nas primeiras 60 horas de vida apresentaram morbidade e intensidade do curso da doença mais baixas, além de não adoecerem antes dos 14 dias de vida. No presente estudo, as baixas mortalidade e letalidade por diarreia podem também ser atribuídas, em parte, a adequada transferência de imunidade passiva em $69,5 \%$ das bezerras, o que provavelmente proporcionou melhor reação do organismo frente às infecções. O sistema de criação em casinhas tem diversas vantagens como evitar a reinfecção das bezerras por microorganismos que possam permanecer viáveis no local, já que utilizam o sistema de rotação e ter facilidade de limpeza, reduzindo assim o risco de diarreia por diversas etiologias (OLIVEIRA; AZEVEDO; MELO, 2005). 
Porém tal sistema de criação, não foi suficiente para impedir a ocorrência de parasitoses no rebanho, embora a presença de cistos nas fezes tenha ocorrido em proporções semelhantes naquelas diarreicas e normais. A alta incidência de parasitos nesta criação, provavelmente, se deve à má higienização do local com relação à retirada do material fecal e à lavagem dos comedouros e bebedouros, observada durante o período do estudo. A higiene e desinfecção de baldes e instalações são fatores fundamentais para o sucesso da criação e desenvolvimento das bezerras (OLIVEIRA; AZEVEDO; MELO, 2005). Segundo Bangoura et al. (2012), a limpeza e desinfecção dos alojamentos dos animais, e a troca de alojamentos são os pilares para o controle da coccidiose em bezerros. Na propriedade estudada apesar de haver um manejo estratégico de rotação das casinhas, não havia um manejo tático, importante para sanar problemas decorrentes de situações de emergência como excesso de chuva ou acúmulo de umidade que pode facilitar a manutenção de formas infectantes de parasitos nas pastagens. Outro aspecto observado nas visitas semanais foi a presença eventual de animais adultos no local das casinhas com consequente eliminação de fezes contaminando a pastagem, provável fonte de infecção para as bezerras. Adicionalmente, moscas, comumente presentes no ambiente das casinhas, são vetores mecânicos de oocistos de Cryptosporidium e cistos de Giardia (CONN et al., 2007).

Apesar de alta, a incidência de diarreia não foi capaz de causar mortalidade possivelmente devido à baixa intensidade das infecções, em parte, ao sistema de criação adotado na propriedade, e ao tratamento que era realizado em casos graves de diarreia, mesmo tendo apresentado algumas deficiências de higiene. A semelhança entre a idade média das bezerras com diarreia e a idade média daquelas que eliminaram oocistos de Cryptosporidium spp. indica que dentre os bioagentes pesquisados este pode estar envolvido nos quadros diarreicos observados, tendo em vista que a diarreia é multifatorial, e outros agentes podem estar presentes neste rebanho.
Este estudo foi realizado em apenas uma propriedade, onde se utilizam tecnologias consideradas como de ponta, tais como, o tipo de fertilização empregado para dar origem a animais com maior valor genético. Todos os animais estavam sob as mesmas condições de manejo e climáticas, diminuindo assim a influência destas variáveis nos resultados. No entanto, independentemente da fonte de colostro e da forma de administração ser mesma para todas as bezerras, o estado imunitário dos animais apresentou diferenças, indicando a importância de se conhecer a presença de falhas na transferência de imunidade passiva para se implantar ações preventivas mais direcionadas.

Este é o primeiro estudo que estima a incidência de diarreia e parasitos gastrintestinais em bezerras até 100 dias criadas em sistema de casinhas tropicais no Estado do Rio de Janeiro. No entanto, mais estudos devem ser realizados envolvendo diversas fazendas e em diferentes regiões para obtenção de dados que possam propiciar acurácia e maior validade externa das informações geradas sobre a incidência de diarreia e parasitos gastrintestinais em rebanhos de bezerras criadas sob o sistema de casinhas.

\section{Agradecimentos}

À Coordenação de Aperfeiçoamento de Pessoal de Nível Superior e a Fundação Carlos Chagas Filho de Amparo à Pesquisa do Estado do Rio de Janeiro (processo E-26/110.228/2010-APQ1).

\section{Referências}

ALMEIDA, V. A.; MAGALHÃES, V. C. S.; NETA, E. S. M.; MUNHOZ, A. D. Frequency of species of the genus Eimeria in naturally infected cattle in Southern Bahia, Northeast Brazil. Revista Brasileira de Parasitologia Veterinária, Jaboticabal, v. 20, n. 1, p. 78-81, 2011.

BANGOURA, B.; MUNDT, H-C.; SCHMÃSCHKL, R.; WESTPHAL, B.; DAUGSECHIES, A. Prevalence of Eimeria bovis and Eimeria zuernii in German cattle herds and factors influencing oocyst excretion. Parasitology Research, New York, v. 110, n. 2, p. 875-881, 2012. 
BARTELS, C. J. M.; HOLZHAUER, M.; JORRITSMA, R.; SWART, W. A. J. M.; LAM, T. J. G. M. Prevalence, prediction and risk factors of enteropathogens in normal and non-normal faeces of young Dutch dairy calves. Preventive Veterinary Medicine, Amsterdam, v. 93, n. 2-3, p. 162-169, 2010.

BARWICK, R. S.; MOHAMMED, H. O.; WHITE, M. E.; BRYANT, R. B. Prevalence of Giardia spp. And Cryptosporidium spp. on dairy farms in southeastern New York state. Preventive Veterinary Medicine, Amsterdam, v. 59, n. 1, p. 1-11, 2003.

BASSO, W. U.; VENTURINI, L.; RISSO, M. A. Comparación de técnicas parasitológicas para el examen de heces de perro. Parasitología al Día, Santiago, v. 22, n. 1-2, p. 52-56, 1998.

BJÖRKMAN, C.; SVENSSON, C.; CHRISTENSSON, B.; VERDIER, K. de. Cryptosporidium parvum and Giardia intestinalis in calf diarrhoea in Sweden. Acta Veterinaria Scandinavica, Copenhagem, v. 44, n. 3-4, p. 145-152, 2003.

BOTTEON, R.C. C. M.; BOTTEON, P. T. L.; SANTOS JÚNIOR, J. C. B.; PINNA, M. H.; LÓSS, Z. G. Freqüência de diarréia em bezerros mestiços sob diferentes condições de manejo na região do médio Paraíba - Rio de Janeiro e Minas Gerais. Brazilian Journal of Veterinary Research and Animal Science, São Paulo, v. 45, n. 2, p. 153-162, 2008.

BOYD, J. W. The relationship between serum immune globulin deficiency and disease in calves: a farm survey. Veterinary Record, London, v. 90, n. 23, p. 645-649, 1972.

BROOK, E.; HART, C. A.; FRENCH, N.; CHRISTLEY, R. Molecular epidemiology of Cryptosporidium subtypes in cattle in England. The Veterinary Journal, Amsterdam, v. 179, n. 3, p. 378-382, 2009.

BROOK, E.; HART, C. A.; FRENCH, N.; CHRISTLEY, R. Prevalence and risk factors for Cryptosporidium spp. infection in young calves. Veterinary Parasitology, Amsterdam v. 152, n. 1-2, p. 46-52, 2008.

BRUHN, F. R. P.; SILVA JÚNIOR, F. A.; CARVALHO, A. H. O.; ORLANDO, D. R.; ROCHA, C. M. B. M. da; GUIMARÃES, A. M. Occurrences of Eimeria spp. and gastrointestinal nematodes in dairy calves in southern Minas Gerais, Brazil. Revista Brasileira de Parasitologia Veterinária, Jaboticabal, v. 21, n. 2, p. 171-175, 2012.

CASTRO-HERMIDA, J. A.; GONZÁLEZ-LOSADA, Y. A.; MEZO-MENÉNDEZ, M.; ARES-MAZÁS, E. A study of cryptosporidiosis in a cohort of neonatal calves. Veterinary Parasitology, Amsterdam, v. 106, n. 1, p. 1117, 2002.
CHARLES, T. P.; CAMPOS, O. F. de; LIZIERE, R. S. Uso do teste de coagulação pelo glutataldeído como indicador do nível de imunoglobulinas no soro de bezerros recémnascidos. Revista da Sociedade Brasileira de Zootecnia, Viçosa, v. 23, n. 1, p. 65-72, 1994.

CONN, D. B.; WEAVER, J.; TAMANG, L.; GRACZYK, T. K. Synanthtopic flies as vectors of Cryptosporidium and Giardia among livestock and wildlife in a multispecies agricultural complex. Vector-Borne and Zoonotic Diseases, New York, v. 7, n. 4, p. 643-651, 2007.

CORNELISSEN, A. W. C. A.; VERSTEGEN, R.; BRAND, H.; PERIE, N. M.; EYSKER, M.; LALM, T. J. G. M.; PIJPERS, A. An observational study of Eimeria species in housed cattle on Dutch dairy farms. Veterinary Parasitology, Amsterdam, v. 56, n. 1-3, p. 7-16, 1995.

De la FUENTE, R.; GARCÍA, A.; RUIZ-SANTAQUITERIA, J. A.; LUZÓN, M.; CID, D.; GARCÍA, S.; ORDEM, J. A.; GÓMEZ-BAUTISTA, M. Proportional morbidity rates of enteropathogens among diarrheic dairy calves in central Spain. Preventive Veterinary Medicine, Amsterdam, v. 36, n. 2, p. 145-152, 1998.

De la FUENTE, R.; LUZÓN, M.; RUIZ-SANTAQUITERIA, J. A.; GARCÍA, A.; CID, D.; ORDEM, J. A.; GARCÍA, S.; SANZ, R.; GÓMEZ-BAUTISTA, M. Cryptosporidium and concurrent infections with other major enterophatogens in 1 to 30 day-old diarrheic dairy calves in central Spain. Veterinary Parasitology, Amsterdam, v. 80, n. 3, p. 179-185, 1999.

DEL COCO, V. F.; CÓRDOBA, M. A.; BASUALDO, J. A. Cryptosporidium infection in calves from a rural area of Buenos Aires, Argentina. Veterinary Parasitology, Amsterdam, v. 158, n. 1-2, p. 31-35, 2008.

ECKERT, J.; BRAUN, R.; SHIRLEY, M. W.; COUDERT, P. COST.89/820. Biotechnology: guidelines on techniques in coccidiosis research. Luxembourg: Office for Official Publications of the European Communities, 1995. 300 p.

FEITOSA, F. L. F.; CAMARGO, D. G.; YANAKA, R.; MENDES, L. C. N.; PEIRÓ, J. R.; BOVINO, F.; LISBOA, J. A. N.; PERRI, S. H. V.; GASPARELLI, E. R. F. Índices de falha de transferência de imunidade passiva (FTIP) em bezerros holandeses e nelore, às 24 e 48 horas de vida: valores de proteína total, de gamaglobulina, de imunoglobulina $\mathrm{G}$ e da atividade sérica de gamaglutamiltransferase, para o diagnóstico de FTIP. Pesquisa Veterinária Brasileira, Rio de Janeiro, v. 30, n. 8, p. 696-704, 2010.

FIGUEIREDO, P. C.; SERRA FREIRE, N. M.; GRISI, L. Eimerias de bovinos leiteiros no Estado do Rio de Janeiro: técnica de diagnóstico e espécies identificadas. Atas da Sociedade de Biologia do Rio de Janeiro, Rio de Janeiro, v. 24, n. 1, p. 3-10, 1984. 
FURMAN-FRATCZAK, K.; RZASA, A.; STEFANIAK, $\mathrm{T}$. The influence of colostral immunoglobulin concentration in heifer calves serum on their health and growth. Journal of Dairy Science, Champaign, v. 94, n. 11, p. 5536-5543, 2011.

GARCÍA,A.; RUIZ-SANTA-QUITERIA, J.A.; ORDEN, J. A.; CID, D.; SANZ, R.; GÓMEZ-BAUTISTA, M.; De La FUENTE, R. Rotavirus and concurrent infections with other enteropathogens in neonatal diarrheic dairy calves in Spain. Comparative Immunology Microbiology Diseases, Califórnia v. 23, n. 3, p. 175-183, 2000.

GEURDEN, T.; VANDERSTICHEL, R.; POHLE, H.; EHSAN, A.; von SAMSON-HIMMELSTJERNA, G.; MORGAN, E. R.; CAMUSET, P.; CAPELLI, G.; VERCRUYSSE, J.; CLAEREBOUT, E. A multicentre prevalence study in Europe on Giardia duodenalis in calves, with molecular identification and risk factor analysis. Veterinary Parasitology, Amsterdam, v. 190, n. 3-4, p. 383-390, 2012.

GUIMARÃES, A. M.; GUEDES, E.; CARVALHO, R. A. Ocorrência de Giardia spp. em bezerros leiteiros no Brasil. Arquivo Brasileiro de Medicina Veterinária e Zootecnia, Belo Horizonte, v. 53, n. 6, p. 652-653, 2001.

GUIMARÃES, L. B.; FACURY FILHO, E. J.; CARVALHO, A. U. de; FERREIRA, P. M.; RIBEIRO, M. F. B.; FERREIRA, M. G.; FREITAS, M. D. Comportamento da excreção de oocistos de Cryptosporidium spp. e de cistos de Giardia spp. em bezerros infectados naturalmente. Ciência Animal Brasileira, Goiânia, v. 10, p.660-665, 2009. Suplemento 1 .

HIN, L. Y.; LAU, T. K.; ROGERS, M. S.; CHANG, A. M. Dichotomization of continuous measurements using generalized additive modeling-application in predicting intrapartum caesarean delivery. Statistics in Medicine, New York, v. 18, n. 9, p. 1101-1110, 1999.

JIMÉNEZ, A. E.; FERNANDÉZ, A.; ALFARRO, R.; DOLZ, G.; VARGAS, B.; EPE, C.; SCHNIEDER, T. A cross-sectional survey of gastrointestinal parasites with dispersal stages in feces from Costa Rican dairy calves. Veterinary Parasitology, Amsterdam, v. 173, n. 1-4, p. 236-246, 2010.

KLOCKIEWICZ, M.; KABA, J.; TOMCZUK, K.; JANECKA, E; SADZIKOWSKI, A. B.; RYPUŁA, K.; STUDZIŃSKA, M.; MAŁECKI-TEPICHT, J. The epidemiology of calf coccidiosis (Eimeria spp.) in Poland. Parasitology Research, New York, v. 101, p. 5121-5128, 2007. Supplement 1.

KONEMAN, E. W.; ALLEN, S. D.; JANDA, W. M.; SCHRECKENBERGER, P. C.; WINN, J. R. Diagnóstico microbiológico. Rio de Janeiro: MEDS, 2008. 1760 p.
LASSEN, B.; VILTROP, A.; RAAPERI, K.; JÄRVIS, T. Eimeria and Cryptosporidium in Estonian dairy farms in regard to age, species, and diarrhea. Veterinary Parasitology, Amsterdam, v. 166, n. 3-4, p. 212-219, 2009.

LEVINE, N. D. Veterinary protozoology. Ames: Iowa State University Press, 1985. 414 p.

LIMA, W. S.; FAKURI, E.; GUIMARÃES, M. P.; MALACCO, M. A. Dinâmica das helmintoses de bovinos de leite na região metalúrgica de Minas Gerais. Revista Brasileira de Parasitologia Veterinária, São Paulo, v. 6, n. 2, p. 97-103, 1997.

MACHADO NETO, R.; FARONI, C. E.; PAULETTI, P.; BESSI, R. Levantamento do manejo de bovinos leiteiros recém-nascidos: desempenho e aquisição de proteção passiva. Revista Brasileira de Zootecnia, Viçosa, v. 33, n. 6, p. 2323-2329, 2004.

MALDONADO-CAMARGO, S.; ATWILL, R. E.; SALTIJERAL-OAXACA, J. A.; HERRERA-ALONSO, L. C. Prevalence of and risk factors for shedding of Cryptosporidium parvum in Holstein Freisian dairy calves in central México. Preventive Veterinary Medicine, Amsterdam, v. 36, n. 2, p. 95-107, 1998.

MARK-CAREW, M. P.; KHAN, Y.; WADE, S. E.; SCHAAF, S.; MOHAMMED, H. O. Incidence of and risks associated with Giardia infections in herds on dairy farms in the New York City Watershed. Acta Veterinaria Scandinavica, Copenhagem, v. 52, n. 44, p. 1-8, 2010.

MARK-CAREW, M. P.; WADE, S. E.; CHANG, Y-F.; SCHAAF, S.; MOHAMMED, H. O. Prevalence of Giardia duodenalis assemblages among dairy herds in the New York City Watershed. Veterinary Parasitology, Amsterdam, v. 185, n. 2-4, p. 151-157, 2012.

MARTIN, S. W.; MEEK, A. H.; WILlEBERG, P. Epidemiología veterinaria: principios y metodos. Zaragoza: Acribia, 1997. 384 p.

MATJILA, P. T.; PENZHORN, B. L. Occurrence and diversity of bovine coccidia at three localities in South África. Veterinary Parasitology, Amsterdam, v. 104, n. 2, p. 93-102, 2002.

MEDRONHO, R. A.; BLOCH, K. V.; RAGGIO LUIZ, R.; WERNECK, G. L. Epidemiologia. São Paulo: Atheneu, 2008. 676 p.

MENEZES, R. de C. A. A. de; LOPES, C. W. G. Epizootiologia da Eimeria arloingi em caprinos na Microrregião Serrana Fluminense, Estado do Rio de Janeiro, Brasil. Revista Universidade Rural, Série Ciências da Vida, Seropédica, v. 17, n. 2, p. 5-12, 1995. 
MOHAMMED, H. O.; WADE, S. E.; SCHAAF, S. Risk factors associated with Cryptosporidium parvum infection on dairy cattle in southeastern New York State. Veterinary Parasitology, Amsterdam, v. 83, n. 1, p. 1-13, 1999.

MUHID, A.; ROBERTSON, I.; NG, J.; YANG, R.; RYAN, U. Prevalence of Giardia spp. infection in preweaned and weaned calves in relation to management factors. The Veterinary Journal, Amsterdam, v. 191, n. 1, p. 135-137, 2012.

O'HANDLEY, R. M.; COCKWILL, C.; McALLISTER, T. A.; JELINSKI, M.; MORCK, D. W.; OLSON, $M$.E. Duration of naturally acquired giardiosis and cryptosporidiosis in dairy calves and their association with diarrhea. Journal of American Veterinary Medicine Association, Schaumburg, v. 214, n. 3, p. 391-396, 1999.

OLIVEIRA, A. A. de; AZEVEDO, H. C.; MELO, C. B. de. Criação de bezerras em sistemas de produção de leite. Brasília, EMBRAPA, 2005. (Circular técnica, n. 1). Disponível em: <http: \www.cpatc.embrapa.br/ publicações 2005/ct-38.pdf>. Acesso em: 24 abr. 2012.

PÉREZ, E.; KUMMELING, A.; JANSSEN, M. M. H.; JIMÉNEZ, C.; ALVARADO, R.; CABALLERO, M.; DONADO, P.; DWINGER, R. H. Infectious agents associated with diarrhoea of calves in the canton of Tilarán, Costa Rica. Preventive Veterinary Medicine, Amsterdam, v. 33, n. 1-4, p. 195-205, 1998.

PIMENTEL NETO, M.; FONSECA, A. H. Epidemiologia das helmintoses pulmonares e gastrintestinais de bezerros em região de baixada do Estado do Rio de Janeiro. Pesquisa Veterinária Brasileira, Rio de Janeiro, v. 22, n. 4, p. 148-152, 2002.

R DEVELOPMENT CORE TEAM. $R$ : a language and environment for statistical computing. Vienna, Áustria: R Foundation for Statistical Computing, 2011. Disponível em: <http://www.R-project.org>. Acesso em: 15 set. 2011.

REBOUÇAS, M. M.; GRASSO, M. P. S.; SPÓSITO, F. E.; AMARAL, V.; SANTOS, S. M.; SILVA, D. M. Prevalência e distribuição de protozoários do gênero Eimeria (Apicomplexa: Eimeriidae) em bovinos nos municípios de Altinópolis, Taquaritinga, São Carlos e Guairá - Estado de São Paulo, Brasil. Revista Brasileira de Parasitologia Veterinária, São Paulo, v. 3, n. 2, p. 125-130, 1994.

ROBERTS, F. H. S.; O'SULLIVAN, J. P. Methods for eggs counts and larval cultures for strongyles infesting the gastrointestinal tract of cattle. Australian Journal of Agricultural Research, Vitoria, v. 1, n. 1, p. 99-102, 1950.
SANTÍN, M.; TROUT, J. M.; FAYER, R. A longitudinal study of cryptosporidiosis in dairy cattle from birth to 2 years of age. Veterinary Parasitology, Amsterdam, v. 155, n. 1-2, p. 15-23, 2008.

A longitudinal study of Giardia duodenalis genotypes in dairy cows from birth to 2 years of age. Veterinary Parasitology, Amsterdam, v. 162, n. 1-2, p. 40-45, 2009.

SARIDAKIS, H. O.; GARED, S. A. El.; VIDOTTO, M. C.; GUTH, B. E. C. Virulence properties of Escherichia coli strains belonging to enteropathogenic (EPEC) serogroups isolated from calves with diarrhea. Veterinary Microbiology, Amsterdam, v. 54, n. 2, p. 145-153, 1997.

SILVA JUNIOR, F. A.; CARVALHO, A. H. O.; ROCHA, C. M. B. M.; GUIMARÃES, A. M. Fatores de risco associados à infecção por Cryptosporidium spp. e Giardia duodenalis em bovinos leiteiros na fase de cria e recria na mesorregião do Campo das Vertentes de Minas Gerais. Pesquisa Veterinária Brasileira, Rio de Janeiro, v. 31, n. 8, p. 690-696, 2011.

SINGH, B. B.; SHARMA, R.; KUMAR, H.; BANGA, H. S.; AULAKH, R. S.; GILL, J. P. S.; SHARMA, J. $\mathrm{K}$. Prevalence of Cryptosporidium parvum infection in Punjab (India) and its association with diarrhea in neonatal dairy calves. Veterinary Parasitology, Amsterdam, v. 40, n. 1-2, p. 162-165, 2006.

SIVULA, N. J.; AMES, T. R.; MARSH, W. E.; WERDIN, R. E. Descreptive epidemiology of morbidity and mortality in Minnesota dairy heifer calves. Preventive Veterinary Medicine, Amsterdam, v. 27, n. 3-4, p. $155-$ 171, 1996.

SNODGRASS, D. R.; TERZOLO, H. R.; SHERWOOD, D.; CAMPBELL, I.; MENZIES, J. D.; SYNGE, B. A. Aetiology of diarrhoea in young calves. Veterinary Record, London, v. 119, n. 2, p. 31-34, 1986.

SOULSBY, E. J. L. Helminths, arthropods and protozoa of domesticated animals. Philadelphia: Lea \& Febiger, 1982. 809 p.

STARKEY, S. R.; WADE, S. E.; SCHAAF, S.; MOHAMMED, H. O. Incidence of Cryptosporidium parvum in the dairy cattle population in a New York City Watershed. Veterinary Parasitology, Amsterdam, v. 131, n. 3-4, p. 197-205, 2005.

SVENSSON, C.; LUNDBORG, K.; EMANUELSON, U.; OLSSON, S.-O. Morbidity in swedish dairy calves from birth to 90 days of age and individual calf-level risk factors for infectious diseases. Preventive Veterinary Medicine, Amsterdam, v. 58, n. 3/4, p. 179-197, 2003. 
TENNANT, B.; BALDWIN, B. H.; BRAUN, R. K.; NORCROSS, N. L.; SANDHOLM, M. Use of the glutaraldehyde coagulation test for detection of hypogammaglobulinemia in neonatal calves. Journal of the American Veterinary Medical Association, Schaumburg, v. 174, n. 8, p. 848-853, 1979.

UENO, H.; GONÇALVES, P. C. Manualpara diagnóstico das helmintoses de ruminantes. 4. ed. Tóquio: Japan International Cooperation Agency, 1998. 143 p.
WADE, S. E.; MOHAMMED, H. O.; SCHAAF, S. L. Epidemiologic study of Giardia sp.infection in dairy cattle in southeastern New York State. Veterinary Parasitology, Amsterdam, v. 89, n. 1, p. 11-21, 2000a.

. Prevalence of Giardia sp., Cryptosporidium parvum and Cryptosporidium muris (C. andersoni) in 109 dairy herds in five countries of southeastern New York. Veterinary Parasitology, Amsterdam, v. 93, n. 1, p. 1-11, 2000b.

WOOD, S. N. Generalized additive models: an introduction with R. Londres: Chapman and Hall/CRC, 2006. 410 p. 
